\title{
Proposta de um aplicativo móvel para percepção de imagens estáticas por alunos com deficiência visual
}

\author{
Jaline Gonçalves Mombach, Daniel Welfer \\ ${ }^{1}$ Programa de Pós-Graduação em Engenharia Elétrica \\ Universidade Federal do Pampa - Campus Alegrete \\ Av. Tiarajú, 810 - Alegrete - RS - Brasil \\ jaline@alunos.unipampa.edu.br, danielwelfer@unipampa.edu.br
}

\begin{abstract}
The perception of static images is one of the biggest problems of people with visual impairments. The traditional approach employed in schools uses learning objects made by hand and with alternative materials. Therefore, this work presents a mobile application to address this problem. The proposed approach uses touchscreens and response vibratory technologies offered by smartphones. The methodology was based on a case study. Preliminary results indicate that the proposed approach is satisfactory when applied to the abstraction of graphics primitives in the context of geometric shapes.
\end{abstract}

Resumo. A percepção de imagens estáticas é um dos maiores problemas enfrentados por pessoas com deficiência visual. A estratégia tradicional empregada nas escolas utiliza objetos de aprendizagem confeccionados manualmente e com materiais alternativos. Portanto, este trabalho apresenta um aplicativo móvel para tratar esse problema. A abordagem explora as telas sensíveis ao toque e a resposta vibratória oferecida pelos smartphones. A metodologia foi baseada em um estudo de caso. Os resultados preliminares indicam que a abordagem proposta é satisfatória quando aplicada à abstração de primitivas gráficas no contexto de formas geométricas.

\section{Introdução}

As políticas de educação inclusiva almejam assegurar o direito à educação para todos, dando ênfase à inclusão de pessoas com deficiência nas instituições de ensino regular. No Brasil, a última publicação do Censo da Educação Superior registrou 23.250 matrículas em cursos de graduação de alunos que possuíam alguma deficiência, sendo que $10 \%$ destes eram cegos e 18\% tinham baixa visão, totalizando 9.245 alunos com deficiência visual ingressantes no ensino superior só no ano 2011. (BRASIL, 2008, 2011). Conforme Coutinho (2011) a maioria destas instituições, por sua vez, não estão aptas para promover, de fato, um ensino igualitário. A autora destaca que a falta de recursos contribui para uma ação pedagógica inadequada, que ocasiona muitas vezes a não permanência desses alunos no ensino superior.

No âmbito computacional, a Sociedade Brasileira de Computação identificou como sendo um dos desafios científicos da década justamente a concepção de sistemas, ferramentas, modelos, métodos, procedimentos e teorias que possam instigar o "Acesso participativo e universal do cidadão brasileiro ao conhecimento" (SBC, 2006). Ademais, o Plano Nacional dos Direitos da Pessoa com Deficiência (BRASIL, 2011) fomenta 
pesquisas para criação de tecnologias assistivas, ou seja, softwares ou hardwares que auxiliem pessoas com deficiência na realização de atividades rotineiras.

Kopecek e Oslejsek (2008) relatam que a percepção de imagens estáticas é um dos maiores problemas para as pessoas com deficiência visual. Na consulta às tecnologias assistivas indicadas para a deficiência visual no Catálogo Nacional de Produtos de Tecnologia Assistiva (MCTI, 2013) são mostrados ampliadores de tela, dispositivos Braille, conversores de texto, leitores de tela, mesas de relevo, identificadores sonoros de cores, entre outros. De modo geral, é notável a carência por tecnologias que auxiliem na abstração de imagens estáticas, pois a grande maioria trata apenas de informação textual ou sensores ambientais.

Dado o exposto, observou-se a importância de desenvolver uma pesquisa científica voltada à criação de recursos tecnológicos para facilitar a realização de atribuições cotidianas das pessoas cegas e com baixa visão, principalmente no que diz respeito à percepção de figuras. Desse modo, nesse trabalho é apresentada uma proposta de aplicativo móvel para percepção de imagens estáticas por pessoas com deficiência visual no escopo escolar.

O artigo está organizado como segue. Na seção 2, apresenta-se os principais métodos descritos nos trabalhos relacionados, tanto métodos manuais como alternativas tecnológicas. Na seção 3, relata-se a metodologia empregada nesta pesquisa, descrevendo-se o estudo de caso em uma escola pública, o desenvolvimento do aplicativo e os materiais utilizados. Por fim, nas seções 4 e 5 analisa-se os resultados obtidos e expõe-se as considerações finais, respectivamente.

\section{Trabalhos relacionados}

No ambiente escolar, a aprendizagem de alguns conceitos está intimamente ligada à visualização dos entes estudados para que o conhecimento seja adquirido mais facilmente (MARCON; NOGUTI, 2012). Logo, as pessoas cegas e com baixa visão precisam de um meio alternativo para a abstração dessas figuras. Bonadiman (2011) ressalta que cabe à instituição de ensino providenciar a adaptação do material didático para os alunos com deficiência visual, visto que esse é um fator determinante para a sua permanência no curso.

$\mathrm{Na}$ literatura podem ser encontradas muitas práticas, que aplicadas em diferentes contextos, tentam amenizar o problema com métodos manuais. Marcon e Noguti (2012) descrevem a experiência no ensino das disciplinas de Geometria Analítica e Álgebra Linear em um curso de Ciência da Computação de uma universidade pública, já Bonadiman (2011) retrata a produção de material didático impresso acessível no contexto do Ensino Superior à Distância. Nogueira (2009) aborda o ensino de cartografia e construção de mapas táteis e Rosa (2012) apresenta alguns jogos químicos para alunos com deficiência visual. Estes trabalhos relatam que as figuras são moldadas com materiais alternativos (lã, palitos, lixa, etc) para que se obtenham texturas perceptíveis que possam ser exploradas tatilmente pelo aluno. Alguns exemplos desse material são mostrados na Figura 1. Apesar destes trabalhos apresentarem resultados satisfatórios na interação com o aluno deficiente visual, os métodos manuais demandam muito tempo para criação dos materiais tateáveis, pois exigem detalhamento minucioso. Salienta-se que alguns destes trabalhos indicam o uso de dispositivos Braille para impressão das figuras. No entanto, muitos 
destes equipamentos além de possuírem um alto custo para aquisição pelas instituições de ensino, também apresentam interface pouco intuitiva, dificultando o seu manuseio. (MARCON; NOGUTI, 2012)

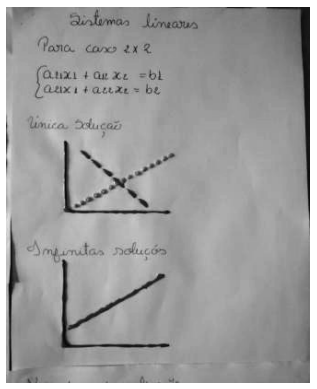

a)



b)

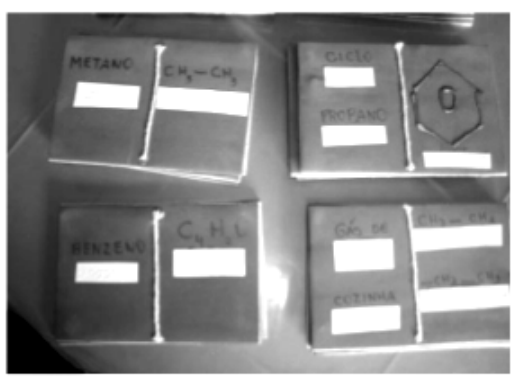

c)

Figura 1. Materiais criados manualmente para exploração tátil de pessoas com deficiência visual: a) Sistemas lineares (MARCON; NOGUTI, 2012); b) Material do caderno de apoio (BONADIMAN, 2011); c) Jogos químicos (ROSA, 2012).

Alternativas computacionais são estudadas para facilitar o processo de adaptação de imagens. Santos Júnior (2009) apresenta uma possibilidade educacional para a percepção de formas geométricas por alunos cegos em placas de pinos acopladas aos computadores. A ideia é que através de uma rede de computadores o professor escolha uma forma geométrica e ela seja formada pelos pinos nas placas dos alunos, para exploração tátil. Toennies et al. (2011) relatam um sistema para o ensino de geometria e demais conceitos matemáticos que usa a vibração e sons emitidos por um computador quando há contato tátil em uma tela externa. Já Dominguez e Graffigna (2011) e Bigham et al. (2010) apresentam soluções para dispositivos móveis: um aplicativo que identifica a cor predominante em um objeto e comunica verbalmente ao usário e o VizWiz::LocateIt, que permite à pessoa com deficiência visual tirar uma foto com o dispositivo e gravar uma pergunta, ambos são encaminhados para uma rede de colaboração voluntária e em pouco tempo é enviada uma resposta verbal ao usuário.

De modo geral, a literatura já provê métodos para o problema da percepção de imagens estáticas por pessoas cegas ou com baixa visão. No entanto, muitos desses métodos apresentam maior preocupação na evolução dos algoritmos e demais técnicas computacionais do que em de fato, auxiliar a pessoa com deficiência visual. Essa questão é facilmente comprovada, quando se analisa os métodos propostos e se verifica que a grande maioria considera a participação do usuário somente no final, na fase de testes. A opinião da pessoa com deficiência visual não é ponderada durante o desenvolvimento da ferramenta, o que resulta muitas vezes em tecnologias sem relevância prática para o usuário. Outra questão importante é o custo a ser investido nesses instrumentos (sensores, computadores com alto desempenho, etc), fator este que dificulta a aquisição dos mesmos pelo público-alvo. Portanto, se considera relevante o desenvolvimento de uma ferramenta que seja conveniente às pessoas com deficiência visual e não tenha um alto custo de investimento.

\section{Materiais e Métodos}

O trabalho foi desenvolvido basicamente em três grandes etapas: observação das técnicas manuais, desenvolvimento do aplicativo de forma iterativa baseado no feedback dos 
usuários e análise dos testes feitos. A proposta é detalhada nas próximas subseções.

\subsection{Metodologia}

A primeira etapa do trabalho consistiu em observações de como era realizada a leitura tátil de imagens estáticas por pessoas cegas com métodos manuais para que fosse elaborada uma proposta tecnológica que proporcionasse meios de interação habituais para o usuário. Observou-se que a percepção da imagem era dada através do acompanhamento sequencial de toque em alguma textura (linha, palito, etc). Logo, foi delineado o desenvolvimento de um aplicativo para dispositivos móveis que consiste na leitura tátil de figuras binárias no dispositivo através do toque na tela touch e das respostas vibratórias, conforme ilustrado na Figura 2. Uma adaptação sonora foi adotada durante o desenvolvimento por recomendação dos usuários no processo de avaliação, descrita ao longo do texto.

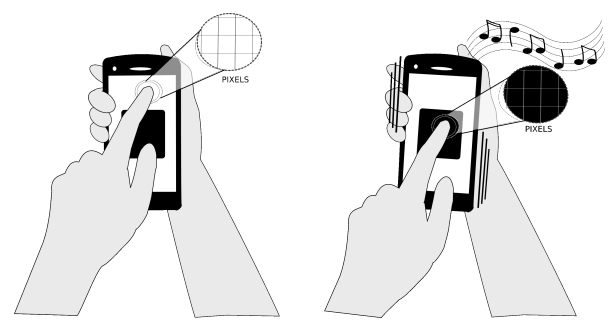

Figura 2. Proposta do aplicativo: se o usuário tocar na tela em um local que remeta a um pixel com valor zero na matriz de pixels da figura, o celular irá vibrar e tocar um som, caso contrário não há ações.

A segunda etapa, de desenvolvimento, foi a mais extensa. O aplicativo foi implementado com uma adaptação livre do modelo espiral (BOEHM, 2001) seguindo as diretrizes do desenvolvimento ágil (BECK et al., 2001) a fim de proporcionar melhor integração com usuários. Nesta etapa adotou-se como metodologia de pesquisa o estudo de caso, realizado em uma escola pública. Por fim, na terceira etapa foi feita a análise dos testes realizados com os alunos durante o desenvolvimento da aplicação.

\subsubsection{Estudo de caso}

O estudo de caso é um método de pesquisa comumente usado para análise de fenômenos individuais, grupais e sociais. O método engloba como atividades principais a observação do ambiente, bem como entrevistas com as pessoas envolvidas (YIN, 2010). Nesse trabalho aplicou-se o estudo de caso para observação de atividades escolares rotineiras dos alunos com deficiência visual, além da avaliação de protótipos durante o desenvolvimento da aplicação.

Essa pesquisa foi desenvolvida em Alegrete/RS, que conta com aproximadamente 77.653 mil habitantes (IBGE, 2010) e não possui centros de apoio específicos para pessoas com deficiência visual. Portanto, a Secretaria Municipal de Educação recomendou a sala de recursos da Escola Estadual de Ensino Fundamental Freitas Valle como unidade de análise pois é a única instituição que realiza atividades com alunos cegos e com baixa visão, além de atender a comunidade externa no município.

A pedagoga que atua na sala de recursos da Escola possui curso de capacitação na área de deficiência visual, atendendo no apoio pedagógico e na reabilitação de pessoas 
que perdem a visão na cidade. A sala é equipada com impressora e máquina de escrever Braille, além de vários materiais táteis. A especialista relata que no ambiente escolar o entendimento de determinados conceitos fica comprometido pela falta de recursos para percepção. Foram citados como exemplo o estudo de mapas, definição de relevo, formas geométricas, distinção de cores e muitos outros temas. No período observado (outubro a dezembro de 2012), a sala de recursos atendia a uma aluna cega, de 16 anos de idade, dois meninos com baixa visão moderada, com 11 e 8 anos de idade e demais alunos que possuíam outras deficiências. As atividades desenvolvidas com os alunos deficientes visuais consistiam basicamente na adaptação do material da aula regular, como transposição de textos em Braille ou ampliação dos mesmos e reforço pedagógico com resolução de exercícios extras sobre o conteúdo trabalhado em sala de aula regular.

\subsubsection{Desenvolvimento do aplicativo}

Como já mencionado, o desenvolvimento foi baseado em uma adaptação livre do modelo espiral, ou seja, um ciclo iterativo com análise, modelagem, implementação e avaliação. Seguindo as diretrizes do desenvolvimento ágil, foram criados protótipos do aplicativo e conforme avaliação dos usuários, foram executadas mudanças. A Figura 3 ilustra as versões implementadas.

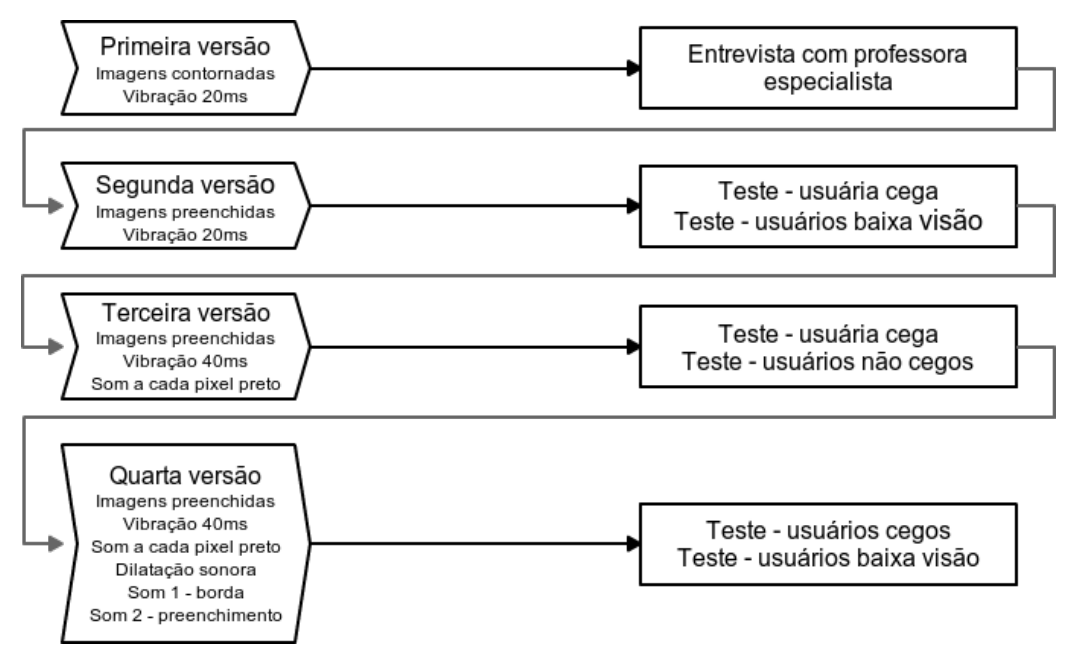

Figura 3. Versões implementadas do aplicativo

A primeira etapa foi o contato com a professora e explicação do método proposto. A ideia inicial era trabalhar de forma automática a imagem para exibição somente do contorno da figura. O contato com a professora especialista teve suma importância nesta etapa, visto que ela indicou que há muitas pessoas cegas com dificuldade na identificação tátil, até mesmo do Braille. Desse modo, sugeriu que não fosse realizada a etapa de reconhecimento do contorno da imagem, pois a noção de preenchimento da figura auxilia consideralvemente no processo de abstração tátil. Também, foi sugerido que as imagens exploradas fossem formas geométricas, um tema que já era de domínio dos alunos.

Depois das considerações da professora especialista foi realizado o primeiro teste com a aluna cega e os alunos com baixa visão usando imagens com formas geométricas 
binárias e preenchidas. A resposta vibratória para cada pixel tocado era de 20 milisegundos. Os alunos com baixa visão não manifestaram sugestões, mas a aluna cega sugeriu o aumento no tempo de vibração e uma forma de reproduzir som: "é difícil reconhecer assim, seria bom vibrar mais e ter um som" (E., 16 anos). Desse modo, na terceira versão o tempo de vibração foi aumentado para 40 milisegundos e adicionado um som do banco público PDSOUNDS (PDSOUNDS, 2013), que tocava cada vez que houvesse toque em um pixel de valor zero. Essa versão foi testada com a aluna cega e com usuários não cegos que tiveram os olhos vendados. A estudante relatou que ainda tinha dificuldade para perceber o que estava "dentro" e "fora", ou seja, o interior da figura e suas extremidades (bordas).

Na quarta versão a modificação foi implementar a dilatação da figura associada a um som. Desse modo, são emitidos dois sinais sonoros distintos, facilitando o reconhecimento da borda da figura. Essa versão não pôde ser testada com a usuária cega, pois a escola já estava em período de férias. Contudo, a versão foi testada com mais uma pessoa cega. A Figura 4 apresenta o diagrama de atividades dessa versão.

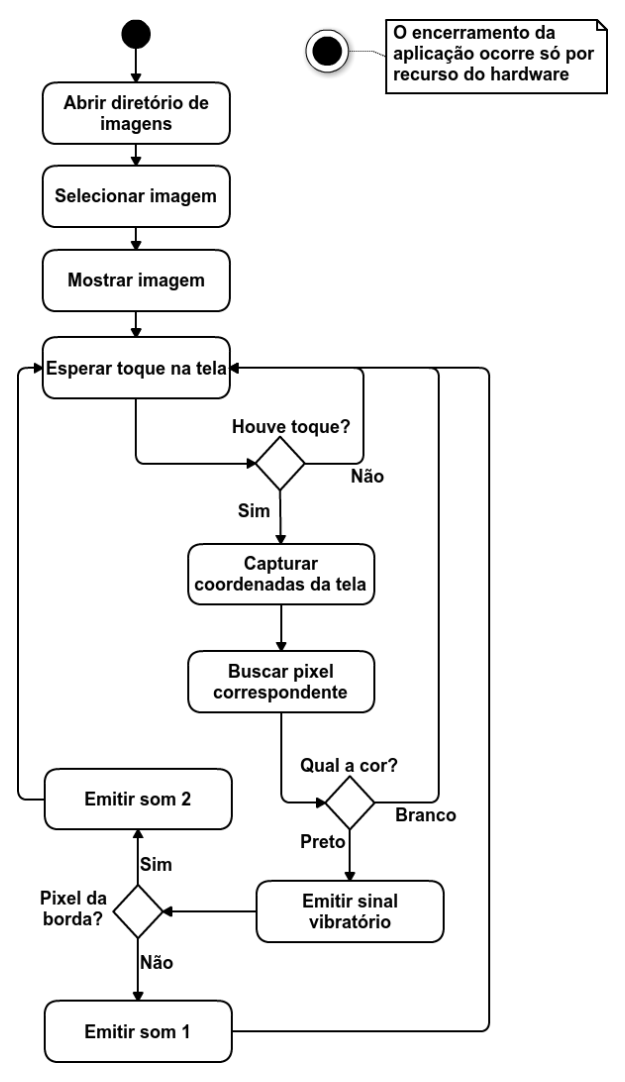

Figura 4. Diagrama de atividades do aplicativo

\subsection{Materiais}

A aplicação foi desenvolvida para o sistema operacional Android (GOOGLE, 2013), versão 2.3. Optou-se por esse sistema devido à sua grande popularização, completude na documentação e facilidade para distribuição dos aplicativos criados. Pesquisas indicam que o sistema operacional Android tem ganhado grande parte do mercado de smartphones, sendo considerado o mais popular (CANALYS, 2012). 
A plataforma de desenvolvimento, conhecido como Android Software Development Kit (SDK), permite a configuração de emuladores para diversas versões, no entanto a versão Android SDK 20.0.3 não dispunha feedback vibratório em emuladores. Portanto, foi usado um dispositivo para o desenvolvimento. $\mathrm{O}$ aparelho utilizado durante a implementação foi um smartphone comum, com display 3,2", processador de $800 \mathrm{MHz}$, memória interna de $150 \mathrm{Mb}$ e sistema operacional Android versão 2.3.3.

As imagens usadas eram primitivas gráficas, ou seja, imagens binárias de formas geométricas, descritas detalhadamente na próxima Seção.

\section{Resultados e Discussões}

\subsection{Teste com usuários}

Foram selecionadas 10 figuras para teste, sob autoria de Sharvit et al. (1998), apresentadas na Figura 5. A estratégia adotada para teste foi carregar as imagens selecionadas no dispositivo, uma de cada vez, e passar o aparelho para a pessoa manipular. Em uma tentativa de obter resultados quantitativos (número de acertos) explicava-se que eram imagens bem simples e que a pessoa deveria tentar adivinhar. Logo o usuário passava a explorar a tela livremente.

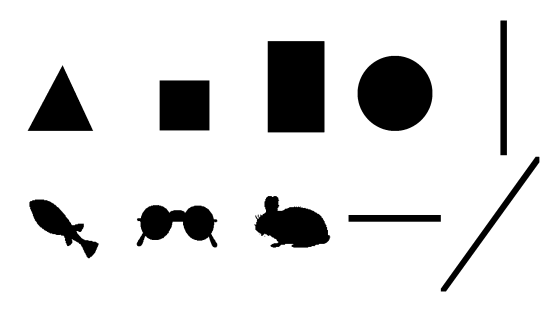

Figura 5. Imagens utilizadas para teste. (SHARVIT et al., 1998)

Os testes foram realizados na sala de recursos da Escola com os alunos deficientes visuais e também com voluntários não cegos (videntes) que tiveram seus olhos vendados, visto que a sala de recursos possuía apenas três usuários para validação do aplicativo. $\mathrm{O}$ perfil dos usuários é descrito na Tabela 1

Tabela 1. Informações sobre os usuários

\begin{tabular}{|l|l|l|l|l|}
\hline \multicolumn{1}{|c|}{ Sigla } & Classificação & \multicolumn{1}{c|}{ Idade } & \multicolumn{1}{c|}{ Escolaridade } & Sexo \\
\hline NC1 & não cego & 10 anos & $3^{\circ}$ ano Ens.Fund & Feminino \\
NC2 & não cego & 12 anos & $5^{\circ}$ ano Ens.Fund & Feminino \\
NC3 & não cego & 11 anos & $4^{\mathrm{o}}$ ano Ens.Fund & Masculino \\
NC4 & não cego & 17 anos & $3^{\mathrm{o}}$ ano Ens.Méd. & Masculino \\
NC5 & não cego & 49 anos & Ens. Médio & Feminino \\
C1 & Cego & 16 anos & $7^{\circ}$ ano Ens.Fund. & Feminino \\
C2 & Cego & 65 anos & Alfabetizada & Feminino \\
BV1 & Baixa visão & 11 anos & $3^{\circ}$ ano Ens.Fund. & Masculino \\
BV2 & Baixa visão & 8 anos & $2^{\circ}$ ano Ens. Fund. & Masculino
\end{tabular}

Nos primeiros testes o reconhecimento da forma foi inviável. Os usuários demonstravam certa ansiedade e descreviam as formas aleatoriamente. Com o passar das iterações de desenvolvimento e o melhoramento da proposta, os resultados foram sendo 
considerados relevantes. A Tabela 2 mostra a junção dos resultados do último teste realizado com usuários não cegos, bem como os realizados com usuários cegos e com baixa visão.

\begin{tabular}{|c|c|c|c|c|c|}
\hline & & & - & $\square$ & \\
\hline NC1 & "Cobra" & "Listra" & "Linha deitada" & "Quadrado" & "Bola" \\
\hline $\mathrm{NC2}$ & "Faixa" & "Pau" & "Tira" & "Triângulo" & "Bola" \\
\hline NC3 & "Listra" & "Listra" & "Listra" & “Quadrado" & "Círculo" \\
\hline NC4 & "Seis" & "Traço" & "Bolinha" & "Cruz" & "Círculo" \\
\hline NC5 & "Boneco" & "Banana" & "Lua" & "Bola" & “Bolinha” \\
\hline C1 & "Linha virada" & "Linha reta" & "Linha deitada" & "Círculo" & "Círculo" \\
\hline C2 & "Fio" & "Fio" & "Fio" & "Bola" & "Bola" \\
\hline BV1 & "Linha virada" & "Linha de pé" & "Linha deitada" & "Círculo" & "Círculo" \\
\hline \multirow[t]{2}{*}{ BV2 } & "Linha" & "Letra I" & "Lista" & "Quadrado" & “Letra U” \\
\hline & & $\Delta$ & $\infty$ & 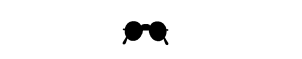 & $x$ \\
\hline NC1 & "Quadrado" & "Pirâmide" & "Círculo" & "Óculos" & "Colher" \\
\hline $\mathrm{NC2}$ & "Quadrado" & "Triângulo" & “Retângulo" & "Formiga" & "Faca" \\
\hline $\mathrm{NC3}$ & "Retângulo" & "Quadrado" & "Triângulo" & "Duas bolas" & "Retângulo" \\
\hline NC4 & "Quadrado" & "Xis" & "Coração" & "Sinal de igualdade" & "Traço" \\
\hline NC5 & "Quadro" & "Laranja" & "Balão" & "Gato" & "Bola" \\
\hline C1 & "Bola" & "Pipa" & "Galinha" & "Estrela" & "Cachorro" \\
\hline C2 & "Bola" & "Xis" & "Bola" & "Duas bolas" & "Pé" \\
\hline BV1 & "Quadrado" & "Triângulo" & "Bola" & "Borboleta" & "Avião" \\
\hline BV2 & "Quadrado" & "Quadrado" & "Triângulo" & "Duas bolas" & "Sapo" \\
\hline
\end{tabular}

Tabela 2. Descrição das figuras pelos usuários

As descrições dos usuários são subjetivas, o que dificulta uma análise quantitativa. No entanto, mesmo que muitas respostas não tenham sido as esperadas, convém ponderar que elas também não podem ser consideradas erradas, pois há certa coerência nas definições dos usuários. Um exemplo desta verificação são as respostas "formiga" do usuário NC2 e "duas bolas" dos usuários NC3, C2 e BV2 para a imagem que representava um óculos (conforme o banco de imagens). De fato, o contorno da figura é similar às caracterizações citadas pelos usuários.

Com o intuito de complementar os testes com usuários foi realizada uma atividade específica com a aluna cega para que ela comparasse a abstração de formas geométricas no modo convencional (manual) e no método proposto (utilizando o aplicativo). A professora especialista colocou sobre uma mesa as cartas de um jogo com formas geométricas tateáveis. Assim, a aluna podia tocar na figura e depois tocar na tela do smartphone e relatar a interação. Em todas as figuras a aluna declarou que era possível perceber o contorno nos dois métodos e a dificuldade encontrada foi quanto ao tamanho da tela do dispositivo (pequena).

Dessa forma, os testes revelaram resultados satisfatórios, visto que os alunos com deficiência visual conseguiram "perceber" a imagem estática através do aplicativo móvel. Consideramos que o objetivo principal do trabalho foi alcançado, já que conseguimos desenvolver uma alternativa tecnológica ao método manual que pode facilitar o processo de adaptação de materiais por professores nas instituições de ensino. 


\section{Considerações Finais}

Este artigo apresentou a proposta de um aplicativo móvel para percepção de imagens estáticas por pessoas com deficiência visual, aplicado ao contexto escolar. O aplicativo encontra-se na quarta versão, já usual. Os resultados preliminares mostraram-se coerentes mas subjetivos, o que inviabilizou a avaliação precisa do aplicativo. Entretanto, os resultados foram satisfatórios se considerado a limitação de hardware utilizado para os testes.

O desenvolvimento do aplicativo partiu de uma proposta que promove a participação ativa dos usuários durante a implementação do sistema, buscando maior aceitação do público-alvo ao produto final, bem como melhor abordagem ao problema real.

A proximidade com usuários cegos e a observação das dificuldades encontradas para realização de atividades rotineiras impulsionou a continuidade da pesquisa, promovendo a ampliação do contexto investigado. Atualmente estão sendo estudadas técnicas de processamento de imagens em dispositivos móveis para o reconhecimento automático de figuras e objetos. Com essa funcionalidade acoplada ao sistema proposto, o aplicativo poderá ser utilizado de forma autônoma pelos usuários cegos, auxiliando também em outras tarefas rotineiras.

\section{Referências}

BECK, K. et al. Manifesto para Desenvolvimento Ágil de Software. 2001.

BIGHAM, J. et al. Vizwiz::locateit - enabling blind people to locate objects in their environment. In: Computer Vision and Pattern Recognition Workshops (CVPRW), 2010 IEEE Computer Society Conference on. [S.1.: s.n.], 2010. p. 65-72. ISSN 2160-7508.

BOEHM. The Spiral Mdel as a Tool for Evolutionary Software Acquisition. 2001. Disponível em: < http://www.stsc.hill.af.mil/crosstalk/2001/05/boehm.html>. Acesso em: 5 de março de 2012.

BONADIMAN, T. C. N. de Q. Produção de material didático para alunos com deficiência visual. Revista Tecnologia \& Cultura, n. 18, p. 61-68, jan/jun 2011.

BRASIL. Decreto n. 7.612/2011, de 17 de novembro de 2011, Institui o Plano Nacional dos Direitos da Pessoa com Deficiência - Plano Viver sem Limite. . Diário Oficial [da] República Federativa do Brasil, Brasília, DF, 18 nov. 2011. Seção 1, p.12.

BRASIL. Ministério da Educação. Secretaria de Educação Especial. Política Nacional de Educação Especial. Brasília, DF, 2008. Disponível em: $<$ http://portal.mec.gov.br/arquivos/pdf/politicaeducespecial.pdf $>$. Acesso em: 28 jun. 2013.

BRASIL. Ministério da Educação. Secretaria de Educação Especial. Microdados Censo da Educação Superior 2011. Brasília, DF, 2011. Disponível em: $<$ http://portal.inep.gov.br/basica-levantamentos-acessar>. Acesso em: 28 jun. 2013.

BRASIL.Ministério da Ciência, Tecnologia e Inovação. Catálogo Nacional de Produtos de Tecnologia Assistiva. 2013. Disponível em: <http://assistiva.mct.gov.br/>. Acesso em: 25 de fevereiro de 2013. 
CANALYS. Smart phones overtake client PCs in 2011. 2012. Disponível em: $<$ http://www.canalys.com/newsroom/smart-phones-overtake-client-pcs-2011>.

COUTINHO, M. de A. A inclusão da pessoa com deficiência visual na educação superior e a construção de suas identidades. Dissertação (Mestrado) — Programa de Pó-Graduação em Educação da Universidade Católica Dom Bosco, Campo Grande, MS, 2011.

DOMINGUEZ, A. L.; GRAFFIGNA, J. P. Colors identification for blind people using cell phone. In: Journal of Physics: Conference Series. [S.1.: s.n.], 2011. v. 332.

GOOGLE. Android. 2013. Disponível em: <http://www.android.com/>. Acesso em: 16 jul. 2013.

Instituto Brasileiro de Geografia e Estatística. Infográficos. 2010. Disponível em: $<$ http://www.ibge.gov.br/cidadesat/painel/painel.php?codmun=430040 $>$. Acesso em: 06 jan. 2013.

KOPECEK, I.; OSLEJSEK, R. Hybrid approach to sonification of color images. In: . Washington, DC, USA: IEEE Computer Society, 2008.

MARCON, D.; NOGUTI, F. C. H. Ensino da disciplina de geometria analítica para alunos com deficiência visual: Relato de uma experiência. In: Escola de Inverno de Educação Matemática. Santa Maria: Universidade Federal de Santa Maria, 2012. Disponível em: <http://goo.gl/Gn9rSS > . Acesso em: 20 de fevereiro de 2013.

NOGUEIRA, R. E. Standardization of tactile maps in brazil. In: International Cartographic Conferences (ICC). Santiago de Chile, Chile: [s.n.], 2009.

PDSOUNDS. Music. 2013. Disponível em: < http://www.pdsounds.org/tag/music >. Acesso em: 22 de fevereiro de 2013.

ROSA, D. L. Aplicação de Metodologias Alternativas para uma Aprendizagem Significativa no ensino de Química. São Mateus, 2012. Monografia. Especialização em Ensino na Educação Básica. Departamento de Educação e Ciências Humanas - Centro Universitário Norte do Espírito Santo. Universidade Federal do Espírito Santo.

SANTOS JÚNIOR, Z. J. A acessibilidade como veículo de inclusão social: proposta de dispositivo computacional para os deficientes visuais da cidade de Natal/RN. Dissertação (Mestrado) - Universidade Federal do Rio Grande do Norte, Curso de Pós-Graduação em Engenharia de Produção, Natal, 2009.

SHARVIT, D. et al. Shape Indexing of Image Databases (SIID). 1998. Disponível em: $<$ http://www.lems.brown.edu/vision/researchAreas/SIID/>. Acesso em: 22 de fevereiro de 2013.

SOCIEDADE BRASILEIRA DE COMPUTAÇÃO. Sociedade Brasileira de Computação: Grandes Desafios da Pesquisa em Computação no Brasil: 2006-2016. [S.1.]: SBC, 2006.

TOENNIES, J. et al. Toward haptic/aural touchscreen display of graphical mathematics for the education of blind students. In: World Haptics Conference (WHC), 2011 IEEE. Istanbul, Turkey: [s.n.], 2011. p. 373-378.

YIN, R. K. Estudo de caso: Planejamento e métodos. 4. ed. Porto Alegre: Bookman, 2010. 